\title{
The effectiveness of retardants moddus and messidor in the cultivation of spring barley on different nutrient status
}

\author{
Alexander Morozov ${ }^{1}$ \\ ${ }^{1}$ Federal State Funded Research Institution «Kursk Federal Agricultural Research Center» 70b, Karl Marx St., Kursk, 305021, Russia
}

\begin{abstract}
The results of field experiments on the effectiveness of the use of retardants Moddus and Messidor in the cultivation of spring barley at different levels of mineral nutrition are presented. The shortening of the second internode of barley plants by $3.3-24.1 \%$ and the increase in its thickness by $1.4-$ $3.7 \%$ were established when using retardants Moddus and Messidor in different doses on a high nutrient content. The data obtained indicates positive effect of retardants on increasing the resistance of barley stems to unfavorable factors (rain and wind), which is confirmed by the results of assessing the degree of lodging. It was found out that the use of retardants on natural nutrient content in a dry growing season leads to the significant decrease in yields (from 0.22 to $0.94 \mathrm{t} / \mathrm{ha}$ ). In slightly arid and excessively humid conditions of the growing season, the use of retardants on medium nutrient content provides the significant increase of the yield from 0.22 to $0.53 \mathrm{t} / \mathrm{ha}$, on high nutrient content - from 0.21 to $0.52 \mathrm{t} / \mathrm{ha}$. In average, over three years of research, the highest yield of barley was obtained on high nutrient content when crops were treated with Messidor at a dose of $1.0 \mathrm{l} / \mathrm{ha}$, Moddus at a dose of $0.4 \mathrm{l} / \mathrm{ha}$. The best economic indicators were established when feed barley was cultivated on medium nutrient content $\left(\mathrm{N}_{15} \mathrm{P}_{39} \mathrm{~K}_{39}+\right.$ pre-seeding application of $\mathrm{N}_{68}$ ) using retardants Moddus at a dose of $0.2 \mathrm{l} / \mathrm{ha}$, Messidor at a dose of $0.5 \mathrm{l} / \mathrm{ha}$.
\end{abstract}

\section{Introduction}

When cultivating spring barley using intensive technology with the yield higher than $6.0 \mathrm{t} / \mathrm{ha}$, further limitation of its productivity growth might be caused by lodging. The negative effect of lodging appears not only in the poorer yield and its quality degradation due to the deterioration of grain filling, but is also one of the main reasons for the losses increase during harvesting. During harvesting of wetter lodged barley, mechanical losses of grain can reach $35 \%$, the productivity of the harvesting equipment decreases and fuel consumption increases, in addition, extra costs are required for drying grain [1].

The probability of lodging of spring barley increases in years with large amount of precipitation, on soils with the high level of fertility with excess nitrogen nutrition, on close planting and sowing varieties with low resistance to lodging $[2,3]$. At the same time, in the shoot stage, a rapid growth of the stem has been observed, which leads to elongation and weakening of the straw, which does not provide sufficient stability during rain and wind. Most often, lodging of spring barley is noticed at the end of the milky phase - the beginning of waxy maturity, when the head has already gained the largest weight. Lodging of barley crops has been also observed in earlier stages of growth due to strong wind and heavy rainfall, which leads to even greater shortfall in grain yield.

The use of retardants is one of the effective measures to prevent lodging, along with the selection of short stem varieties, use of balanced mineral nutrition, split nitrogen fertilizers application in small doses and formation of optimal plant population based on correctly established seeding rate [4-8]. When cultivating spike cereals, including spring barley, it is recommended to use preparations such as Moddus and Messidor.

The preparation Moddus is intended to prevent lodging and is a concentrate of trinexapac-ethyl emulsion $(250 \mathrm{~g} / \mathrm{l})$. Its action is based on inhibition of key enzymes activity involved in the gibberellin biosynthesis, which provides reduction of stem elongation and increases the culm wall thickness, favors the root growth $[9,10]$.

Messidor is a suspension concentrate containing mepiquat chloride (300 g/l) and calcium prohexadione (50 $\mathrm{g} / \mathrm{l})$. The preparation inhibits the synthesis of gibberellins, which prevents cells elongation during the growth process. This ensures the resistance of plants to lodging by shortening and strengthening the stem [11-13].

However, these retardant growth regulators are recommended for application on spring barley in the range 
of consumption rates, regardless of the effect of mineral fertilizers on plant growth. Determining the optimal dose of these preparations, taking into account different levels of mineral nutrition, will not only increase the efficiency of their use, but also reach the potential of cultivated varieties of spring barley in terms of yield.

Based on aforesaid, the aim of the research was to study the effectiveness of the use of retardants Moddus and Messidor in the cultivation of spring feed barley of different nutrient status in the chernozem soils of Kursk region.

\section{Objects and Methods}

The studies were carried out from 2018 to 2020 at Zashchitnoye-Sever LLC., Shchigrovsky District, Kursk Region. The object of the research is a mid-season, intensive variety of spring barley Paustian, included in the State Register for the Central Black Earth Region and recommended for cultivation in Kursk region [14].

The soil of the experimental field is leached chernozem of heavy loamy granulometric composition, with an average content of humus in the plow layer $5.2 \%$, a low content of alkaline hydrolyzable nitrogen $10.5 \mathrm{mg}$, average labile phosphorus - $7.9 \mathrm{mg}$ and high exchangeable potassium - $13.3 \mathrm{mg} / 100 \mathrm{~g}$ of soil. The reaction of the soil is subacidic with $\mathrm{pH}(\mathrm{KCl})-5.2$.

The experiment was based on the method of split plots in four replicates with a systematic arrangement of variants in three layers. The total area of the plot is $240 \mathrm{~m}^{2}$, the accounting area is $220 \mathrm{~m}^{2}$.

The two-factor experiment scheme involved studying the doses of retardants Moddus and Messidor on three nutrient content: natural, medium and high.

The natural nutrient status is without fertilization. The demand of plants for nutrients is covered by natural soil fertility. The medium nutrient status included the main application of mineral fertilizers $\mathrm{N}_{15} \mathrm{P}_{39} \mathrm{~K}_{39} \mathrm{~kg} / \mathrm{ha}$ of active ingredients (diammofoska $150 \mathrm{~kg} / \mathrm{ha}$ ) and pre-seeding application of $\mathrm{N}_{68} \mathrm{~kg} / \mathrm{ha}$ of active ingredients (ammonium nitrate $200 \mathrm{~kg} / \mathrm{ha}$ ). The high nutrient status included the main application of mineral fertilizers $\mathrm{N}_{27} \mathrm{P}_{70} \mathrm{~K}_{70} \mathrm{~kg} / \mathrm{ha}$ of active ingredients (diammofoska $270 \mathrm{~kg} / \mathrm{ha}$ ), pre-seeding application of $\mathrm{N}_{68} \mathrm{~kg} / \mathrm{ha}$ of active ingredients (ammonium nitrate $200 \mathrm{~kg} / \mathrm{ha}$ ) and nitrogen fertilization $\mathrm{N}_{34} \mathrm{~kg} / \mathrm{ha}$ of active ingredients (ammonium nitrate $100 \mathrm{~kg} / \mathrm{ha}$ ) in the shoot phase.

The study of retardants included the control (without treatment), three variants with the treatment of crops with Moddus at a dose of $0.2,0.4,0.6 \mathrm{l} / \mathrm{ha}$ and three options with the treatment of crops with Messidor at a dose of 0.5 , 1.0, $1.5 \mathrm{l} / \mathrm{ha}$. The treatment of barley crops with retardants was carried out in the tillering phase (DC 23-24).

Barley sowing was carried out during optimal calendar period with row spacing of $12.5 \mathrm{~cm}$ and a seeding rate of 3.5 million pieces/ha; the preceding crop was soybeans. The rest agrotechnical methods of cultivation of spring feed barley were standard for the farms of Kursk region.
In the course of the research, the length and thickness of internodes of barley plants in the heading phase were determined. The resistance of barley crops to lodging was evaluated from one to five according to the methodology of the State variety testing of agricultural crops. The yield of barley was determined by the method of complete accounting with recalculation to standard moisture content and purity of $100 \%$. The experimental data were statistically processed by analysis of variance method.

During research years, the meteorological conditions of the growing seasons of spring barley differed and developed as follows: in 2018, it was characterized as arid with high temperature conditions (hydrothermal index - 0.95); 2019 - slightly arid with moderate temperature (hydrothermal index - 1.26); 2020 excessively humid and cool (hydrothermal index-1.93).

\section{Results and Discussion}

Lodging of barley under the conditions of 2018 was observed only on high nutrient content in the control variant (4 points), in 2019 - on high and medium nutrient content (3-4 points in control), in 2020 it showed up in a greater degree not only on high and medium status (2-3 points in control), but also on the natural nutrient content ( 4 points in control).

As a rule, the reason for lodging with excessive soil moisture and mineral nutrition of plants (especially nitrogen) is the rapid stem growth in the shoot stage. This leads to its elongation and weakening and in the subsequent phases of development under adversity (heavy rain and wind) to lodging due to the bending of the lower part of the second internode [15]. In this case, the action of retardants consists in strengthening the lower internodes by their shortening and thickening, which makes the stem more resistant to lodging [16].

Studies in the excessively humid year of 2020 showed that the use of retardants on high nutrient content reduced the length and increased the thickness of the second internode of barley plants (Fig. 1). Compared to the control, the length of internodes in the variants treated with Moddus and Messidor preparations decreased by $16.7-24.1 \%$ and $3.3-11.1 \%$, and their thickness increased by $2.7-3.4 \%$ and $1.4-3.7 \%$, respectively. This was most noticeable when the crops were treated with Moddus at doses of 0.4 and 0.6 1/ha, Messidor - at a dose of $1.01 /$ ha. 


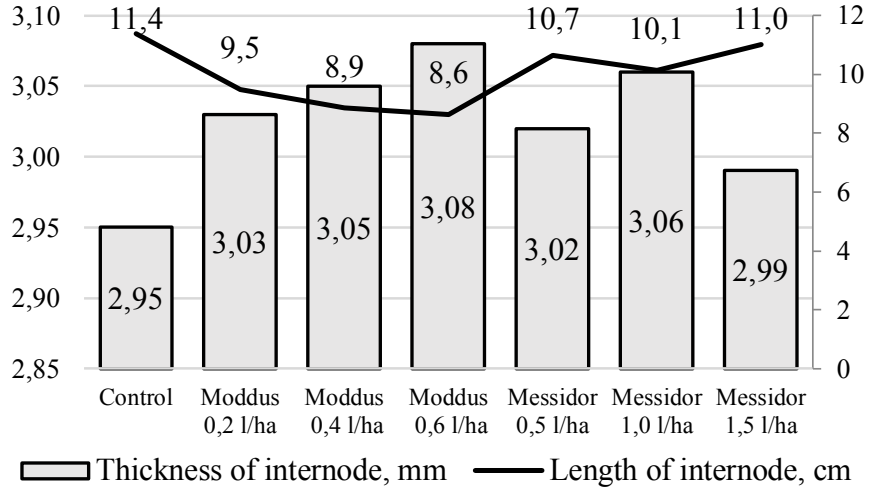

Fig. 1. Impact of retardants doses on the thickness and length of the second internode of spring barley (high nutrient status).

A decrease in the length and an increase in thickness of the second internode of barley plants in variants treated with retardants reflect increased resistance to adverse factors (heavy rainfall and strong wind) that cause lodging. It is confirmed by the results of evaluation of spring barley lodging degree over three years of research (Fig. 2.).

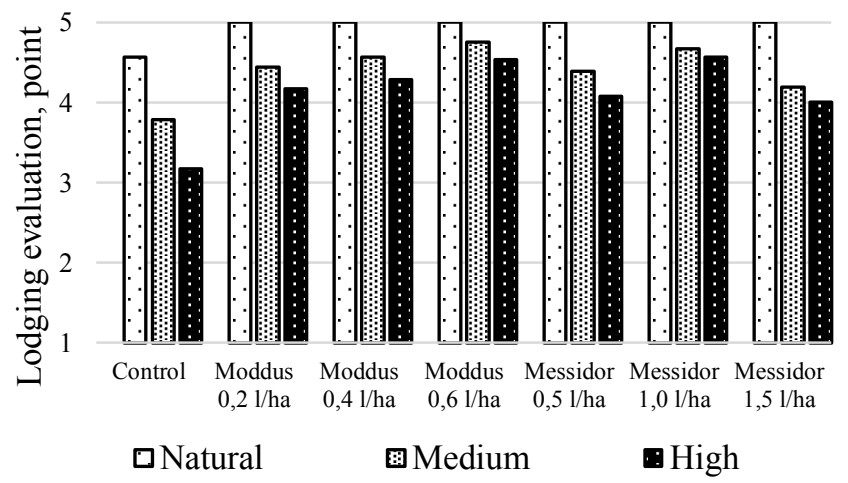

Fig. 2. Impact of nutrient status and retardant doses on the resistance of barley crops to lodging in years 2018-2020.

Thus, the greatest resistance to lodging was recorded when using the preparation Moddus at a dose of $0.6 \mathrm{l} / \mathrm{ha}$. At the same time, the degree of lodging on medium nutrient content was 4.6 points, and on high nutrient content 4.3 points, which was 0.8 and 1.1 points higher than the control, respectively. In the variants with the Messidor preparation, the highest barley resistance to lodging was noted when treated at a dose of $1.0 \mathrm{l} / \mathrm{ha}$ and was 4.7 points on medium nutrient content, 4.6 points on high nutrient content, which is 0.9 and 1.4 points higher than the control, respectively.

The use of retardants on different nutrient status influenced the yield of spring barley (Table 1). On natural nutrient content, retardants Moddus at a dose of $0.6 \mathrm{l} / \mathrm{ha}$ and Messidor at a dose of $1.0 \mathrm{l} / \mathrm{ha}$ authentically reduced the yield of barley practically in all years of research. This was especially noticeable in the dry year of 2018, when treatment with Moddus at doses of 0.4-0.6 1/ha and Messidor, regardless of the application rate, led to the significant (from 0.22 to $0.94 \mathrm{t} / \mathrm{ha}$ ) yield decrease. It should be noted that the treatment of barley crops with retardants on medium and high nutrient content in dry conditions of the growing season revealed only insignificant increase or decrease in yield.

Table 1. The yield of spring barley, t/ha (2018-2020).

\begin{tabular}{|c|c|c|c|}
\hline \multirow{2}{*}{ Retardant dose } & \multicolumn{3}{|c|}{ Nutrient Status } \\
\hline & Natural & Medium & High \\
\hline Control & 5.32 & 6.32 & 6.46 \\
\hline Moddus 0.2 1/ha & 5.21 & 6.55 & 6.71 \\
\hline Moddus 0.4 1/ha & 5.04 & 6.56 & 6.72 \\
\hline Moddus 0.6 1/ha & 4.53 & 6.51 & 6.72 \\
\hline Messidor $0.5 \mathrm{l} / \mathrm{ha}$ & 5.10 & 6.54 & 6.66 \\
\hline Messidor $1.0 \mathrm{l} / \mathrm{ha}$ & 5.06 & 6.58 & 6.77 \\
\hline Messidor 1.5 1/ha & 5.17 & 6.57 & 6.62 \\
\hline \multicolumn{4}{|c|}{$\begin{array}{l}\mathrm{HCP}_{05} \text { according to nutrient content: } 2018 \text { г. }-0.11 \text {; } \\
2019 \text { г. }-0.14 ; 2020 \text { г. }-0.13 \text {. }\end{array}$} \\
\hline \multicolumn{4}{|c|}{$\begin{array}{l}\mathrm{HCP}_{05} \text { according to retardant dose: } 2018 \text { г. }-0.17 ; 2019 \\
\text { г. }-0.21 ; 2020 \text { г. }-0.19 \text {. }\end{array}$} \\
\hline \multicolumn{4}{|c|}{$\begin{array}{l}\mathrm{HCP}_{05} \text { generalized: } 2018 \text { г. }-0.29 ; 2019 \text { г. }-0.36 ; 2020 \\
\text { г. }-0.33 \text {. }\end{array}$} \\
\hline
\end{tabular}

On meduim nutrient content in years with slightly arid and excessively humid growing seasons of barley, treatment of crops with retardants, regardless application rate, provided a statistically authentic increase of the yield (from 0.22 to $0.53 \mathrm{t} / \mathrm{ha}$ ). They also provided similar significant increase of yield (from 0.21 to $0.52 \mathrm{t} / \mathrm{ha}$ ) on high nutrient content, except for the crops treated with Messidor at a dose of $1.5 \mathrm{l} / \mathrm{ha}$ under excessive moisture conditions of the growing season.

Analysis of yield data on average for three years of research showed that the maximum yield of spring barley was obtained from the treatment of crops with Messidor at a dose of $1.0 \mathrm{l} / \mathrm{ha}$ and was $6.58 \mathrm{t} / \mathrm{ha}$ on medium nutrient content, and $6.77 \mathrm{t} / \mathrm{ha}$ on high nutrient content. At the same time, the yield increase in comparison with the control on medium nutrient content was $0.26 \mathrm{t} / \mathrm{ha}$, and on high nutrient content was $0.31 \mathrm{t} / \mathrm{ha}$. The retardant Moddus, on medium and high nutrient content, provided the highest yield of barley grain -6.56 and $6.72 \mathrm{t} / \mathrm{ha}$ when crops was treated at a dose of $0.41 /$ ha, where, in comparison with the control, the yield increase was 0.24 and $0.26 \mathrm{t} / \mathrm{ha}$, respectively.

The calculation of the economic effectiveness of the spring barley cultivation for fodder showed that the cost of products obtained on medium and high nutrient content with treatment with retardants in almost all doses compared with the control outweighs the higher production costs and ensures the increase of the qualified net income per hectare (Table 2).

Table 2. Nutrient status impact and retardant influence on economic effectiveness of spring barley cultivation (2018-2020). 


\begin{tabular}{|l|l|l|l|l|}
\hline Retardant dose & $\begin{array}{c}\text { Cost of } \\
\text { product } \\
\text { Rub./ha }\end{array}$ & $\begin{array}{c}\text { Produc- } \\
\text { tion } \\
\text { costs, } \\
\text { Rub./ha }\end{array}$ & $\begin{array}{c}\text { Prime } \\
\text { cost of } \\
\text { products, } \\
\text { Rub./t }\end{array}$ & $\begin{array}{c}\text { Qualified } \\
\text { net } \\
\text { income, } \\
\text { Rub./ha }\end{array}$ \\
\hline \multicolumn{5}{|c|}{ Medium nutrient status } \\
\hline Control & 71766 & 29417 & 4658 & 42350 \\
\hline Moddus 0.2 1/ha & 74427 & 30370 & 4637 & 44057 \\
\hline Moddus 0.4 1/ha & 74519 & 30862 & 4706 & 43657 \\
\hline Moddus 0.6 1/ha & 73964 & 31354 & 4817 & 42609 \\
\hline Messidor 0.5 1/ha & 74304 & 30604 & 4680 & 43701 \\
\hline Messidor 1.0 1/ha & 74791 & 31329 & 4760 & 43463 \\
\hline Messidor 1.5 1/ha & 74690 & 32054 & 4877 & 42637 \\
\hline \multicolumn{5}{|c|}{ High nutrient status } \\
\hline Control & 73385 & 33891 & 5248 & 39494 \\
\hline Moddus 0.2 1/ha & 76199 & 34845 & 5197 & 41354 \\
\hline Moddus 0.4 1/ha & 76392 & 35337 & 5257 & 41055 \\
\hline Moddus 0.6 1/ha & 76328 & 35829 & 5334 & 40499 \\
\hline Messidor 0.5 1/ha & 75720 & 35078 & 5265 & 40642 \\
\hline Messidor 1.0 1/ha & 76872 & 35803 & 5293 & 41069 \\
\hline Messidor 1.5 1/ha & 75213 & 36528 & 5519 & 38685 \\
\hline
\end{tabular}

The highest values of the qualified net income of $44,057.00 \mathrm{rubles} / \mathrm{ha}$, with the minimum production cost of 4,637.00 rubles/t, were obtained during barley cultivation on medium nutrient content using the Moddus retardant at a dose of 0.2 1/ha. When using the retardant Messidor, the highest qualified net income of $43,701.00 \mathrm{rubles} / \mathrm{ha}$ and the minimum production cost of $4,680.00$ rubles/t were in the variant of barley cultivation of medium nutrient status with crop treatment at a dose of $0.5 \mathrm{l} / \mathrm{ha}$.

The treatment of crops with retardants on high nutrient content, although allowed to obtain higher cost of cultivated products $(75,213.00-76,872.00$ rubles/ha), however, because of production costs increase $(34,845.00$ $36,528.00 \mathrm{rubles} / \mathrm{ha}$ ), led to the increase of the prime cost of 1 ton of grain by 517-642 RUB and to the decrease of qualified net income by 2,110-3,952 rubles/ha.

\section{Conclusion}

The research results have defined that the use of retardants Moddus and Messidor is an effective agrotechnical method for increasing the resistance of crops to lodging, that provides the increase of spring barley yield on medium nutrient content by $3.0-4.1 \%$, on high nutrient content by $2.5-4.8 \%$ on average, over three years. The use of retardants on natural nutrient content is not advisable due to decrease of barley yield and economic slowdown.

The crops treatment with retardants on high nutrient content does not provide sufficiently high level of yield, which, along with increased production costs, leads to the escalation of the prime cost of cultivated products and to the decrease of qualified net income. The variants of spring barley cultivation on medium nutrient content with the use of retardants Moddus at a dose of $0.2 \mathrm{l} / \mathrm{ha}$ and Messidor at a dose of $0.5 \mathrm{l} / \mathrm{ha}$ were economically most profitable.

\section{References}

1. F.I. Privalov, Protection and quarantine of plants, 12, 24-26 (2004)

2. M.B. Hkokonova, O.K. Tsagoeva, Altay State Agriculture University Bulletin, 6 (176), 26-30 (2019)

3. O.V. Ashaeva, Yu.S. Baluev, Scientific journal Cube GAU, 161 (07), 1-9 (2020)

4. R.M. Gafurov, V.M. Rakhimov, A.A. Molodchuev, Agrotechnical Bulletin, 4, 20-21 (2012)

5. A.A. Smirnov, Z.A. Kirasirov, N.A. Kuryatnikova, Scientific and Technical Achievements of AIC, 2, 3536 (2008)

6. S.B. Govorkova, R.M. Gafurov, V.A. Tsymbalova, E.V. Kalabashkina, Agriculture, 5, 39-41 (2019)

7. A. Rajala, P. Peltonen-Sainio, M. Onnela, M. Jackson, Plant Growth Regulation, 38 (1), 51-59 (2002)

8. N. Khan, A. Baber, A. M. D. Bano, Plos one, 15 (4), e0231426 (2020)

9. E.V. Malygin, K.A. Vinokurova, Protection and quarantine of plants, 7, 49-50 (2011)

10. O.A. Shapoval, V.V. Vakulenko, I.P. Mozharova, Protection and quarantine of plants, 8, 4-7 (2010)

11. V.I. Panasin, S.I. Novikova, D.A. Rymarenko, Fertility, 3, 14-15 (2015)

12. A.I. Mykhlyk, S.V. Lazarevich, Bulletin of the Belarusian State Agricultural Academy, 1, 73-77 (2015)

13. S.B. Govorkova, V.A. Tsymbalova, Yu.V. Tuchkina, E.V. Kalabashkina, R.M. Gafurov, Agrochemical Bulletin, 1, 56-58 (2019)

14. State Register of breeding achievements approved for use, 1 (Plant varieties), 680 (2020)

15. V.N. Obraztsov, S.V. Kadyrov, V.A. Fedotov, Voronezh State Agrarian University Bulletin, 1 (64), 61-68 (2020)

16. V.F. Vaschenko, V.V. Nam, Agricultural biology, 6, 119-122 (2013) 